\title{
Physiological Profile of Brazilian Elite Soccer Players: Comparison between U-17, U-20 and professionals
}

\author{
Carlos Herdy' ${ }^{1}$ Pablo B. Costa ${ }^{2}$, Roberto Simão ${ }^{3}$, James Selfe ${ }^{4}$
}

'Estácio de Sá University, Graduate Program in Physical Education, Rio de Janeiro, Brazil, ${ }^{2}$ California State University, Exercise Physiology Laboratory, Department of Kinesiology, Fullerton, USA, ${ }^{3}$ Federal University of Rio de Janeiro, Physical Education Graduate Program, Rio de Janeiro, Brazil, ${ }^{4}$ University of Central Lancashire, School of Sport, Tourism and the Outdoors, Preston, UK

\begin{abstract}
Possible differences in the physical values related to characteristics of the age group and the play positions in soccer. The aims to analyze the isokinetic muscle strength profiles, anthropometric, neuromuscular and cardiovascular characteristics, comparing age, categories and play positions. 105 players divided into U-17, U-20, Professional and six play positions. The isokinetic test, anthropometric measurements, counter-movement jump test with arms and yo-yo intermittent recovery test were performed. Significant differences $(p<0.05)$ were found in the professionals compared to U-20 and U-17 for body mass, height, body fat, $\mathrm{VO}_{2 \max }$ and for U-17 in relation to professionals in the isokinetic test. Significant differences were also found between play positions $(p<0.05)$ for body mass, height, $\mathrm{VO}_{2 \max }$ and isokinetic. Soccer athletes playing in different positions have different profiles of physiological characteristics and U-17 have a lower level of strength compared to professionals, suggesting the importance of training specificity.
\end{abstract}

Key words: Soccer, Muscle Strength Dynamometer, Youth Sports

\section{Introduction}

One of the main factors affecting soccer performance is muscle strength (Brown \& Weir, 2011). Knowledge of strength levels in players is therefore important for a proper training prescription in order to gain optimal performance (Hamzeh \& Head, 2004). The strength of soccer players has been previously studied by measuring squats and vertical jumps (Dauty, Bryand, \& PotironJosse, 2002; Silva et al., 2012; Wisløff, Helgerud, \& Hoff, 1998), as well as by specific strength tests using isokinetic dynamometry (Agre \& Baxter, 1987; Gioftsidou et al., 2008; Hamzeh \& Head, 2004; Hom, Steen, \& Olstad, 2005). Studies have demonstrated muscle strength increases as young athletes grow and develop (Le Gall, Laurent, \& Rochcongar, 1999), and that muscle balance is fundamental for young players in order to advance to levels of excellence using specific training (Hom, Steen, \& Olstad, 2005).

Normally, two factors tend to cause injuries in soccer play- ers. The first is the agonist-antagonist imbalance between the quadriceps and hamstrings. The second is the contra lateral strength imbalance between the dominant and non-dominant limbs (Daneshjoo, Rahnama, Mokhtar \&Yusof, 2013). These imbalances have been identified as a common occurrence and can potentially increase the risk of injury (Hamzeh \& Head, 2004; Lehance, Binet, Bury, \& Croisier, 2008; Bulatović \& Kezunović, 2011; Tsikanos, Paschoalis, \& Valasotiris, 2016). The incidence of knee injuries due to soccer practice has become a concern to clubs and athletes of all age groups, both in individuals who practice this sport recreationally as well as in professional athletes. Young people age 16-20 years are involved in intense periods of technical, tactical, and physical training with the aim, to be promoted to the professional squad in the long-term (Gioftsidou et al., 2008). Consequently, this prolonged and intense training may lead to muscle imbalance and injuries.

\section{Correspondence:}

\section{Montenegro C. Herdy}

Sport Universidade Estácio de Sá - Campus Ilha do Governador, Laboratório de Fisiologia do Exercício - LAFIEX, Rua Sargento João Lópes, 1900 - Jardim Carioca - 21931420 - Rio de Janeiro, RJ - Brasil

E-mail: carlosherdy@gmail.com 
Studies demonstrate significant cardiovascular, anthropometric, maturation, and physical differences among age categories (Lago-Peñas, Casais, Dellal, Rey, \& Domínguez, 2011; Silva, Bloomfield, \& Marins, 2008) and between field positions in amateur and professional athletes (Keiner, Sander, Wirth \& Hartmann, 2015). At each position, the player uses a specific style of play which directs the development of a particular musculoskeletal profile (Hencken \& White, 2006). The availability of reference values for knee extensor and flexor strength has become an important additional factor for improving training prescriptions and the prevention of injuries. Thus, the purpose of this study was to examine the muscle strength, anthropometric and cardiovascular profiles of athletes from an elite soccer club in the under 17 years of age (U-17), under 20 years of age (U-20), and adult professional (AP) categories, and to explore relationships with their playing positions.

\section{Methods}

Subjects

The sample was composed of 105 male soccer players from a first division club in Brazil participated in the study. They were divided into three age categories: U-17, U-20 and AP. Their playing positions were recorded as goalkeeper, external defenders, central defender, defensive midfield, midfielder and forward. The players had at least five years of training experience in high performance soccer. To be included in the study, all subjects had to have performed isokinetic testing before the study and have no medical history that could be aggravated by participation in resistance training. Participants were also directed to abstain from any nutritional or ergogenic supplements. The Faulkner protocol was used for body fat analysis (Faulkner, 1968), the counter-movement jump test (with arms) was used for vertical jump height (Silva et al., 2012) and the yo-yo intermittent recovery test was used to estimate the maximum oxygen consumption $\left(\mathrm{VO}_{2 \max }\right)$ (Castagna, Impellizzeri, Chamari, Carlomagno, \& Rampinini, 2006). All subjects were instructed to refrain from participating in any physical training during the study period, except those prescribed as part of the investigation. We obtained the assent and consent from all participants and their respective legal guardians and this study followed international standards for working with human beings (World Medical Association, 2013) and was approved in Research Ethics Committee of the Federal University of Rio de Janeiro, with the number
34315478.7.0000.5257, in accordance with Resolution 196/96 of the Brazilian Health Council.

\section{Isokinetic testing}

An isokinetic dynamometer (Technogym ${ }^{\circledR}$, REV9000, Italy) was used for strength assessments. Subjects performed five sub maximal familiarization tests. The order of the limb testing was randomly selected. The concentric tests of the hamstrings and quadriceps were performed at $60 \% \mathrm{~s}$ with five maximal repetitions. A standardized pretest procedure was employed, where all athletes received instructions on the test purposes, as well as on the procedures for performing the test. A 5-min warm up was performed using a cycle ergometer at a speed of $80 \mathrm{rpm}$ and power at $50 \mathrm{~W}$. The environmental conditions during the tests were: ambient temperature $21.8 \pm 1.20{ }^{\circ} \mathrm{C}(20-24)$, barometric pressure of $702.7 \pm 1.4$ $\mathrm{mmHg}(700-705)$ and relative humidity percentage $52.1 \pm 14.9 \%$ (28-71). The isokinetic strength test was undertaken in the seated position $\left(120^{\circ}\right.$ hip angle). Subjects were stabilized by belts attached to the chest, hip, and thigh of the tested limb. Participants crossed their arms over the chest to minimize involvement of upper body musculature. The lateral femoral condyle was aligned with the axis of rotation of the dynamometer while the ankle cuff was attached proximally to the lateral malleolus. Gravitational correction was performed to account for limb mass. Subjects were tested by the same examiner who encouraged the athlete with verbal commands throughout the test to perform with their maximal effort.

\section{Statistical Analyses}

All data are presented as mean $( \pm S D)$. A Kolmogorov-Smirnov test (Bartlett criterion) was performed to assess the normality and homoscedasticity of the data. All variables presented normal distribution and homoscedasticity. An ANOVA with repeated measures was performed with Bonferoni post-hoc tests when appropriate, to examine the differences between the flexors and extensors knee torque measures of the dominant and non-dominant limbs and to identify possible differences between the groups. The significance level was set at $p<0.05$. Data were analyzed using SPSS Version 21 (SPSS Inc., Chicago, IL, USA), which analysis was used to determine the differences in 6 play positions.

\section{Results}

Data on the composition of the sample containing the values of age, anthropometric data (body mass and stature), fat percent-

Table 1. Mean \pm S.D. values for characteristics of athletes separated by categories U-17, U-20 and AP.

\begin{tabular}{cccc}
\hline Categories & $\mathbf{U}-\mathbf{1 7}$ & $\mathbf{U}-\mathbf{2 0}$ & AP \\
\hline ( $n=105)$ & 35 & 35 & 35 \\
Age (years) & $16.72 \pm 0.11$ & $18.78 \pm 0.24$ & $23.40 \pm 0.85$ \\
Mass (kg) & $70.96 \pm 3.69$ & $72.01 \pm 8.04$ & $79.97 \pm 7.26^{*}$ \\
Height (cm) & $177.40 \pm 4.52$ & $175.90 \pm 5.98$ & $182.20 \pm 6.6^{*}$ \\
Body Fat (\%) & $12.49 \pm 0.60$ & $12.76 \pm 1.37$ & $11.21 \pm 0.48^{*}$ \\
Vertical Jump (cm) & $53.94 \pm 5.93$ & $54.12 \pm 2.83$ & $48.69 \pm 1.95^{*}$ \\
$\mathrm{VO}_{2 \max }$ (ml-kg·min) & $59.03 \pm 2.33$ & $59.03 \pm 1.72$ & $52.93 \pm 2.63^{*}$ \\
\hline
\end{tabular}

${ }^{*}$ Represents significant differences $(\mathrm{p}<0.05)$ between AP vs. U-17 and U-20 for mass; ${ }^{*}$ Represents significant differences $(p<0.05)$ between AP vs. U-17 and U-20 for height, * Represents significant differences $(p<0.05)$ between AP vs. U-17 and $U-20$ for body fat, ${ }^{*}$ Represents significant differences $(p<0.05)$ between Professional vs. $U-17$ and $U-20$ for vertical jump; *Represents significant differences $(p<0.05)$ between AP vs. U-17 and U-20 for $\mathrm{VO}_{2 m}$ Statistical Analysis: ANOVA with post hoc Bonferroni.

age, vertical jump and maximum $\mathrm{VO}_{2}$ (Mean \pm S.D.), can be observed in Table 1 divided by category.

In table 2 it's possible observe the same variables of Table
1, however, divided by the playing position, regardless of the category.

Significant differences in flexion and extension strength 
Table 2. Mean \pm S.D. values for characteristics of athletes separated by playing positions.

\begin{tabular}{ccccccc}
\hline & Goalkeeper & $\begin{array}{c}\text { External } \\
\text { Defender }\end{array}$ & $\begin{array}{c}\text { Central } \\
\text { Defender }\end{array}$ & $\begin{array}{c}\text { Defensive } \\
\text { Midfielder }\end{array}$ & $\begin{array}{c}\text { Central } \\
\text { Midfielder }\end{array}$ & Forward \\
\hline$n$ & 12 & 18 & 17 & 20 & 22 & 16 \\
Age (years) & $19.76 \pm 2.30$ & $19.67 \pm 1.66$ & $20.01 \pm 1.30$ & $19.48 \pm 1.15$ & $19.72 \pm 1.28$ & $19.16 \pm 1.37$ \\
Mass (kg) & $85.10 \pm 5.43^{*}$ & $70.42 \pm 3.65$ & $77.50 \pm 5.54 \dagger$ & $73.53 \pm 3.83$ & $70.33 \pm 7.12$ & $71.38 \pm 4.92$ \\
Height (cm) & $186.58 \pm 2.70^{*}$ & $172.51 \pm 4.41^{*}$ & $182.43 \pm 4.98^{*}$ & $176.94 \pm 3.48$ & $175.12 \pm 6.64$ & $177.75 \pm 4.71$ \\
Body Fat (\%) & $12.75 \pm 1.40$ & $12.19 \pm 1.28$ & $12.67 \pm 1.97$ & $11.07 \pm 1.15$ & $11.97 \pm 1.82$ & $12.41 \pm 1.78$ \\
Vertical Jump (cm) & $53.30 \pm 3.72$ & $49.67 \pm 3.62$ & $51.64 \pm 4.86$ & $52.70 \pm 5.32$ & $48.38 \pm 3.33$ & $52.71 \pm 5.50$ \\
VO $_{2 \max }$ (ml-kg·min) & $53.60 \pm 1.83^{*}$ & $58.75 \pm 3.12$ & $55.75 \pm 1.78$ & $57.22 \pm 2.36$ & $58.74 \pm 2.47$ & $56.24 \pm 1.93$ \\
\hline
\end{tabular}

*Represents significant differences $(p<0.05)$ between goalkeepers vs. external defender, central defender, defensive midfielder, central midfielder and forward for mass; *Represents significant differences $(p<0.05)$ between central defender vs. central midfielder for mass; ${ }^{*}$ Represents significant differences $(p<0.05)$ between goalkeeper vs. external defender, defensive midfielder, central midfielder and forward for height; *Represents significant differences $(p<0.05)$ between external defenders vs. central defender for height; ${ }^{*}$ Represents significant differences $(p<0.05)$ between central defender vs. central midfielder for height; *Represents significant differences $(p<0.05)$ between goalkeeper vs. external defenders and central midfielder for $\mathrm{VO}_{2 \max }$. Statistical Analysis: ANOVA with post hoc Bonferroni.

among the age categories and among the playing positions were noted and outlined in tables 3 and 4 . U-17 players had significantly lower flexion strength $(\mathrm{p}<0.05)$ in both sides and a lower dominant-side $\mathrm{H}$ :Q ratio compared to AP players. In regards to position, goalkeepers displayed higher values than the other positions as follows: dominant quadriceps compared

Table 3. Mean \pm S.D. values for isokinetic strength separated by categories $U-17, U-20$ and AP.

\begin{tabular}{cccc}
\hline & U-17 & U-20 & AP \\
\hline Quadriceps (D) (Nm) & $240.90 \pm 34.30$ & $249.60 \pm 37.20$ & $248.50 \pm 44.30$ \\
Hamstrings (D) (Nm) & $136.10 \pm 22.20^{*}$ & $153.10 \pm 34.90$ & $157.20 \pm 44.40$ \\
Quadriceps (ND) (Nm) & $235.60 \pm 26.30$ & $263.10 \pm 38.00$ & $250.60 \pm 46.40$ \\
Hamstrings (ND) (Nm) & $128.60 \pm 23.40^{*}$ & $147.90 \pm 28.60$ & $148.40 \pm 39.40$ \\
\hline H:Q (D) (Nm/kgbw) & $0.57 \pm 0.08^{*}$ & $0.59 \pm 0.09$ & $0.63 \pm 0.09$ \\
H:Q (ND) (Nm/kgbw) & $0.54 \pm 0.07$ & $0.55 \pm 0.08$ & $0.59 \pm 0.09$ \\
Bilateral Q:Q (Nm/kgbw) & $0.01 \pm 0.09$ & $0.04 \pm 0.10$ & $0.01 \pm 0.13$ \\
Bilateral H:H (Nm/kgbw) & $0.05 \pm 0.14$ & $0.02 \pm 0.11$ & $0.06 \pm 0.12$ \\
\hline
\end{tabular}

Note: D: dominant; ND: non-dominant; Q: quadriceps; H: hamstrings.

${ }^{*}$ Represents significant differences $(p<0.05)$ between U-17 vs. AP for dominant hamstrings; ${ }^{*}$ Represents significant differences $(p<0.05)$ between U-17 vs. AP for non-dominant hamstrings; *Represents significant differences $(p<0.05)$ between U-17 vs AP for H:Q - dominant. Statistical Analysis: ANOVA with post hoc Bonferroni.

to central midfielder $(\mathrm{p}<0.05)$, dominant hamstrings compared to external defenders, defensive midfielders, central midfielders, and forwards $(\mathrm{p}<0.05)$. These differences were also noted with respect to the non-dominant hamstrings and the dominant $\mathrm{H}: \mathrm{Q}$ ratio compared to external defenders and central midfielders, as well as bilateral strength $(\mathrm{H} / \mathrm{H})$ com-

Table 4. Mean \pm S.D. values for isokinetic strength separated by playing positions.

\begin{tabular}{|c|c|c|c|c|c|c|}
\hline & Goalkeeper & $\begin{array}{l}\text { External } \\
\text { Defender }\end{array}$ & $\begin{array}{c}\text { Central } \\
\text { Defender }\end{array}$ & $\begin{array}{l}\text { Defensive } \\
\text { Midfielder }\end{array}$ & $\begin{array}{c}\text { Central } \\
\text { Midfielder }\end{array}$ & Forwards \\
\hline $\mathrm{Q}(\mathrm{D})(\mathrm{Nm})$ & $278.02 \pm 52.02 *$ & $230.98 \pm 2.80$ & $263.76 \pm 9.08$ & $251.91 \pm 19.11$ & $224.21 \pm 12.23$ & $254.27 \pm 8.85$ \\
\hline $\mathrm{H}(\mathrm{D})(\mathrm{Nm})$ & $203.63 \pm 66.59 *$ & $129.50 \pm 9.79$ & $158.61 \pm 14.75^{*}$ & $151.30 \pm 7.92$ & $128.30 \pm 9.88$ & $147.54 \pm 19.89$ \\
\hline $\mathrm{Q}$ (ND) (Nm) & $286.44 \pm 61.17$ & $238.65 \pm 11.09$ & $260.02 \pm 15.21$ & $247.68 \pm 19.61$ & $233.15 \pm 18.39$ & $253.84 \pm 14.75$ \\
\hline $\mathrm{H}(\mathrm{ND})(\mathrm{Nm})$ & $174.80 \pm 57.10^{*}$ & $123.43 \pm 3.63$ & $149.20 \pm 12.23$ & $144.22 \pm 2.33$ & $124.23 \pm 11.73$ & $146.72 \pm 11.70$ \\
\hline $\begin{array}{c}\mathrm{H}: \mathrm{Q}(\mathrm{D}) \\
(\mathrm{Nm} / \mathrm{kgbw})\end{array}$ & $0.71 \pm 0.10^{*}$ & $0.56 \pm 0.03$ & $0.60 \pm 0.04$ & $0.60 \pm 0.01$ & $0.57 \pm 0.01$ & $0.58 \pm 0.07$ \\
\hline $\begin{array}{c}\mathrm{H}: \mathrm{Q}(\mathrm{ND}) \\
(\mathrm{Nm} / \mathrm{kgbw})\end{array}$ & $0.59 \pm 0.07$ & $0.51 \pm 0.02$ & $0.57 \pm 0.02$ & $0.58 \pm 0.03$ & $0.53 \pm 0.01$ & $0.57 \pm 0.03$ \\
\hline $\begin{array}{c}\text { Bilateral Q:Q } \\
(\mathrm{Nm} / \mathrm{kgbw})\end{array}$ & $0.00 \pm 0.09$ & $0.04 \pm 0.13$ & $0.01 \pm 0.10$ & $0.01 \pm 0.07$ & $0.04 \pm 0.11$ & $0.01 \pm 0.12$ \\
\hline $\begin{array}{c}\text { Bilateral H:H } \\
(\mathrm{Nm} / \mathrm{kgbw})\end{array}$ & $0.13 \pm 0.06 \|$ & $0.05 \pm 0.07$ & $0.06 \pm 0.10$ & $0.07 \pm 0.10$ & $0.04 \pm 0.10$ & $0.02 \pm 0.21$ \\
\hline
\end{tabular}

Note: Q: quadriceps; $\mathrm{H}$ : hamstrings.

* Represents significant differences $(\mathrm{p}<0.05)$ between goalkeeper vs. central midfielder dominant quadriceps; ${ }^{*}$ Represents significant differences $(p<0.05)$ between goalkeeper vs. external defenders, defensive midfielder, central midfielder and forward dominant hamstring; ${ }^{*}$ Represents significant differences $(p<0.05)$ between central defender vs. central midfielder dominant hamstring; ${ }^{*}$ Represents significant differences $(p<0.05)$ between goalkeeper vs. external defenders and central midfielder non-dominant hamstring; ${ }^{*}$ Represents significant differences $(p<0.05)$ between goalkeeper vs. external defenders and central midfielder $\mathrm{H}: \mathrm{Q}$ - dominant; ${ }^{*}$ Represents significant differences $(\mathrm{p}<0.05)$ between goalkeeper vs. forward bilateral $\mathrm{H} / \mathrm{H}$. Statistical Analysis: ANOVA with post hoc Bonferroni. 
pared to the forwards $(\mathrm{p}<0.05)$.

Significant differences $(\mathrm{p}<0.05)$ were found between the U-17 and AP players for knee flexion of the dominant and non-dominant knee flexion, and for the dominant $\mathrm{H}$ :Q ratio (Table 3).

In addition, the goalkeepers demonstrated significant differences compared to all other playing positions (Table 4) ( $\mathrm{p}<$ $0.05)$.

\section{Discussion}

The main conclusion of the present study is that soccer athletes in different playing positions have different isokinetic strength, anthropometric, and cardiovascular profiles. In addition, the current study confirmed players in the U-17 category have lower strength levels compared to professional adult athletes. Thus, in line with Hom et al. (2005) and Lehance et al (2008), we found U-17 athletes had lower peak torque values than adult professionals. In addition, the current data demonstrated goalkeepers were distinguished by higher strength values compared to the other positions. The height variation in the goalkeepers could be attributed to the fact that taller players were chosen for this position in addition to being more effective in placing the ball back in play because they perform numerous goal kicks during training and games.

Our results corroborate the findings of a recent study by Tsikanos et al. (2016) examining 275 professional soccer players that reported highest knee extension isokinetic strength values for goalkeepers at three angular velocities $30 \%, \mathrm{~s}, 60 \%$, and $90 \%$ s. In this sense, with respect to the field positions, we demonstrated significant differences between goalkeepers and most other positions examined. For instance, our data suggest the bilateral strength $(\mathrm{H} / \mathrm{H})$ in the forwards was significantly lower than in goalkeepers. Lago-Peñas et al. (2011) also highlighted the fact goalkeepers were different from other soccer athletes given their training specificity. However, conflicting with our data, Tsikanos et al. (2016) did not report differences among field positions after examining peak torque relative to body mass in professional Greek soccer players. These conflicting results were probably because Tsikanos et al. (2016) studied professional athletes and analyzed four positions while in the present study we also analyzed the U-17 and U-20 categories in six different positions. In addition, Tsikanos et al. (2016) only analyzed the dominant leg, which may have been a limiting factor for inferences. Thus, our results point to the need of specific training approaches for different age categories and playing positions.

Silva et al. (2012) reported the level of muscle power in soccer athletes, and examined different categories and positions using the vertical jump test. No significant differences were reported among the U-17, U-20 and adult professional categories, although it was noted there were differences between midfielders and defenders. Tourney-Chollet et al. (2000) also found significant differences related to forwards and midfielders hamstrings, though the study examined only three playing positions of adult teams. While their ages differed across the three categories, test subjects were highly trained in the present study.

The present data demonstrated significant differences between central defenders and central midfielders' hamstrings peak torque of the dominant leg. Soccer is a complex sport and playing and training in a certain position can stimulate different power levels. However, this relationship is not well described in the literature and needs further investigation. The observation and analysis of categories and positions played on the field is of great importance for professionals who aim at reaching the best results and developing injury prevention protocols.

In the case of $\mathrm{VO}_{2 \max } \mathrm{AP}$ had lower values than younger athletes. Although athletic individuals demonstrate a non-linear decline upon decreasing or ceasing training, the normal age-related decline in $\mathrm{VO}_{2 \max }$ is reported at approximately $10 \%$ per decade regardless of activity level (Hawkins \& Wiswell, 2003). This demonstrates that older professional soccer athletes need to pay greater attention to the aerobic training component. Previous studies have observed little difference between the playing positions in men (Lockie, Lazar et al., 2016). However, the respective measurements were: anthropometrical measures, jump assessments, linear non-linear speed tests or featured only indirect muscular endurance tests. Future investigations involving the measurement of physiological, chemical and functional parameters (Lago-Peñas et al., 2011) are suggested to extrapolate the real relationship between the ages and categories of soccer players.

In conclusion, the U-20 did not present significant statistical difference for the physical characteristics evaluated in relation to the AP. While, U-17 do not have the same strength, anthropometric and cardiovascular profiles compared to AP. This finding can be explained by the fact that athletes in this age group are still in the process of growth and maturation incomplete, which would affect isokinetic strength levels. In addition, players in different positions have different physical and physiological characteristics (particularly goalkeepers and forwards), suggesting the importance of specific training for each position. Professionals involved with sports training, strength, conditioning, and rehabilitation are therefore alerted to review the training and rehabilitation procedures used with younger soccer players and to consider tailoring these to the athletes playing position.

\section{Acknowledgements}

There are no acknowledgements.

\section{Conflict of Interest}

The authors declare that there are no conflict of interest.

Received: 10 May 2018| Accepted: 01 June 2018 | Published: 13 July 2018

\section{References}

Agre, J., \& Baxter, T. L. (1987). Musculoskeletal profile of male collegiate soccer players. Archives of Physical Medicine and Rehabilitation, 68(3), $147-150$.

Brown, L. E. E., \& Weir, J. (2001). Procedures recommendation I: accurate assessment of muscular strength and power. Journal of Exercise Physiology, 4(3), 1-21.

Bulatović, N., \& Kezunović, M. (2011). Ethiology and mechanisms of injuries of knee anterior cruciate ligament in athletes. Sport Mont, 9(28-29-30), 257-264.

Castagna, C., Impellizzeri, F., Chamari, K., Carlomagno, D., \& Rampinini, E. (2006). Aerobic fitness and yo-yo continuous and intermittent tests performances in soccer players: a correlation study. The Journal of Strength \& Conditioning Research, 20(2), 320-325.

Daneshjoo A., Rahnama N., Mokhtar A.H., \&Yusof A. (2013). Bilateral and unilateral asymmetries of isokinetic strength and flexibility in male young professional soccer players. Journal Of Human Kinetics, 36(1), 45-53.

Dauty, M., Bryand, F., \& Potiron-Josse, M. (2002). Relation between isokinetic torque, jump and sprint in high-level soccer player. Science \& Sports, 17(3), 122-127.

Faulkner, J. A (1968). Physiology of swimming and diving. In: Falls, H.. Exercise physiology. Baltimore: Academic Press. 
Gioftsidou, A., Ispirlidis, I., Pafis, G., Malliou, P., Bikos, C., \& Godolias, G. (2008) Isokinetic strength training program for muscular imbalances in professional soccer players. Sport Sciences for Health, 2(3), 101-105.

Hamzeh, M., \& Head, A. (2004). Isokinetic hamstrings and quadriceps evaluation of professional soccer players. Journal of Sports Sciences, 22 265-266.

Hawkins, S. A., \& Wiswell, R. A. (2003). Rate and mechanism of maximal oxygen consumption decline with aging. Sports Medicine, 33(12), 877-888.

Hencken, C., \& White, C. (2006). Anthropometric assessment of Premiership soccer players in relation to playing position. European Journal of Sport Science, 6(4), 205-211.

Hom, I., Steen, H., \& Olstad, M. (2005). Isokinetic muscle performance in growing boys from pre-teen to maturity. An eleven-year longitudina study. Isokinetics and Exercise Science, 13(2),153-158.

Keiner, M., Sander, A., Wirth, K., \& Hartmann, H. (2015). Differences in the performance tests of the fast and slow stretch and shortening cycle among professional, amateur and elite youth soccer players. Journal Of Human Sport And Exercise, 10(2),563-570.

Lago-Peñas, C., Casais, L., Dellal, A., Rey, E., \& Domínguez, E. (2011). Anthropometric and physiological characteristics of young soccer players ac cording to their playing positions: relevance for competition success. The Journal of Strength \& Conditioning Research, 25(12), 3358-3367.

Le Gall, F., Laurent, T., \& Rochcongar, P. (1999). Improvement in hamstring and quadriceps strength in high level soccer players. Science \& Sports, 14(4), 167-172.

Lehance, C., Binet, J., Bury, T., \& Croisier, J. L. (2008). Muscular strength, func tional performances and injury risk in professional and junior elite soc- cer players. Scandinavian Journal of Medicine \& Science in Sports, 19(2) 243-51.

Lockie, R. G., Lazar, A., Orjalo, A. J., Davis, D. L., Moreno, M. R., Risso, F. G., Hank M. E., Stone, R. C., \& Mosich, N. W. (2016). Profiling of junior college football players and differences between position groups. Sports, 4(3), 1-17.

Ortega, J. I., Evangelio, C., Clemente, F.M., Martins, F. M. L., \& González-Víllora, S. (2016). Analysis of physiological, technical, and tactical analysis during a friendly football match of elite U19. Sports, 4(2), 35-49.

Silva, C. D., Bloomfield, J., \& Marins, J. C. (2008). A review of stature, body mass and maximal oxygen uptake profiles of under 17, under 20 and first division players in Brazilian soccer. Journal of Sports Science and Medicine, 7(3), 309-319.

Silva, J. F., Detanico, D., Floriano, L. T., Dittrich, N., Nascimento, P. C., Santos, S. G., \& Guglielmo, L. G. A. (2012). Níveis de potência muscular em atletas de futebol e futsal em diferentes categorias e posições. Motricidade, $8(1), 14-22$.

Tourny-Chollet C., Leroy D., L'eger H., \& Beuret-Blanquart F. (2000). Isokinetic knee muscle strength of soccer players according to their position. Isokinetics and Exercise Science, 8(4), 187-193.

Tsikanos, A., Paschoalis, V., \& Valasotiris, K. (2016). Knee extension strength profile of elite Greek soccer players. Isokinetics and Exercise Science, 24(1), 79-82.

Wisløff, J., Helgerud, J., \& Hoff, J. (1998). Strength and endurance of elite soccer players. Medicine and Science in Sports and Exercise, 30(3), 462-467.

World Medical Association. (2013). World Medical Association Declaration of Helsinki: ethical principles for medical research involving human subjects. JAMA, 310(20), 2191-2194. 